\title{
Indirect preparative-analytical gas chromatographic technique for mass spectrometric identification of rum composition'
}

\author{
Heriberto Batiz
}

\begin{abstract}
A gas chromatograph-mass spectrometer (GC.MS) at the Rum Pilot Plant (RPP) is contributing significantly toward the production of high quality rum. This GC-MS permits better prediction and control of the quality of distilled spirits and fermented products. Since rum cannot be fully analyzed directly with GC-MS because many of its components are at extremely low concentrations, different techniques are being considered for preparing concentrates suitable for study by this instrument. The technique reported here uses an indirect approach, where the sample is concentrated in a preservative column and subsequently retained in a small trap. Finally the product is quantitatively transferred and sealed in a small vial for further analysis with the flame ionization decector (FID) or the CG-MS. This chromatographic technique was evaluated successfully. Data obtained resulfed in about 1000-fold improvement in the concentration of components in their own matrix compared with that of the neat rum. The vast majority of components resolved with the new technique are at concentrations below $0.01 \mathrm{mg} / 100 \mathrm{ml}$ and numerous compounds separated in the chromatogram have not previously been observed in Puerto Rican rums.
\end{abstract}

\section{RESUMEN}

Identificación de la composición del ron por cromatógrafo de gasespectrómetro de masa

La adquisición por la Planta Piloto de Ron (PPR) de un cromatógrafo de gas espectrómetro de masa (CG-EM), ha contribuido a mantener vigorosa la industria de ron al poder predecir y controlar mejor la calidad de los productos. No obstante, este instrumento no puede usarse para analizar completamente los rones porque las concentraciones de muchos de sus componentes son muy bajas y para analizarlos se requieren técnicas de concentración. Se están investigando varios procedimientos para obtener concentrados de los rones. Uno de estos procedimientos se evalúb en la PPR. Esta publicación informa los resultados de la evaluación. La muestra se concentra en una columna preparatoria; el concentrado se retiene en una trampa pequeña y luego se analiza en una columna de alta eficiencia con el detector de ionización de llama (DIF o el CG-EM). Los datos obtenidos arrojaron un grado de concentración de más de 1,000 en la concentración de la muestra respecto al ron original. La gran mayoría de los componentes se encuentran a una concentración por debajo de $0.01 \mathrm{mg} . / 100 \mathrm{ml}$. Muchos de los componentes separados en el cromatograma no se habian detectado antes en los rones de Puerto Rico.

'Manuscript submitted to Editorial Board 28 June 1990.

${ }^{2}$ Consultant, Rum Pilot Plant. 


\section{IN'CRODUCTION}

A complete characterization of compounds present in large as well as in minute amounts in fermented products, distilled spirits, and rums is essential for quality assessment. Such information is necessary if the rum industry continues to compete in the present day world market. For this reason the Rum Pilot Plant (RPP) maintains a strong program of research in the composition of alcoholic beverages. Now that the Rum Pilot Plant has a gas chromatograph-mass spectrometer (GC-MS), it can perform a more complete analysis of rums and other related products. The GC-MS can separate and further identify in these materials compounds which may account for the specific character of the beverage. However, alcoholic beverages, as is the case with many other materials, such as environmental samples, have a large number of compounds which cannot be detected directly in the neat sample upon separation by GC. This lack of detection occurs because the MS and the flame ionization detector (FID) do not have enough sensitivity when the concentration of compounds in the sample is very low. In Puerto Rican rums there are many compounds present in such low concentrations that it is necessary to concentrate the sample in the ethanol-water matrix at least 1000 -fold in order to detect and measure the compounds with any degree of accuracy.

Many techniques have been considered to concentrate extremely dilute solutions suitable for FID or GC-MS detection. These techniques include a) solvent extraction using liquid-liquid techniques followed by concentration in a rotatory evaporator; b) separation in a preparative column and injecting the fraction or fractions directly in analytical GC columns; c) adsorption procedures using selected solid adsorbents followed by sample recovery using an appropriate solvent or by heat desorption. However, rapid and direct methods for these procedures without sample contamination are required for rum analysis with GC-MS and high pressure liquid chromatography-mass spectrometry (HPLC-MS).

Some of these techniques have been investigated at the RPP with success in concentrating the compounds of rum, but the lack of a GC-MS prevented further research $(1,5,6)$. Recently these procedures have been extended for indirect and direct separations of rum components with GC-MS utilizing a preparative column coupled to a capillary column for FID or GC detection $(2,3)$. This publication reports the development of an indirect GC technique adapted to conduct preparative GC separation together with high performance gas chromatography (HPGC), using either analytical or preparative columns to concentrate the rum and subsequent analytical separation of compounds in the concentrates by FID or MS detection (8).

The characterization and quantitative determination of alcohols, aldehydes, ketones, organic acids and many other organic substances such 
as traces of nitrosamine and ethyl carbamate $(7,8)$ are of great importance in assessing quality of beverages not only for taste characteristics. Also if compounds which are known to be unhealthy are found in the beverages, they may be reduced to acceptable levels or eliminated from the product. The flavor of alcoholic beverages is composed of many different volatile and nonvolatile compounds, which give a beverage its typical odor and taste. Nearly 1,000 compounds have been identified in different beverages $(9,10,12,13)$. Fusel alcohols, fatty acids, and esters form the largest groups of compounds in the volatile aroma fraction of alcoholic beverages. Other components, such as phenols, carbonyl, nitrogen and sulfur compounds, are in minor quantities, but their contribution to the overall quality of the beverages is significant. In imported foreign rums the number of compounds identified is more restricted than in other beverages, such as whiskeys, but still about 400 compounds have been identified (11). In Puerto Rican rum the components separated are fewer $(2,3,4)$.

\section{MATERIALS AND METHODS}

Equipment

A Hewlett Packard (HP-5750A) GC was adapted to conduct preparative separation simultaneously with high efficiency analytical determination (fig. 1) and to perform the indirect separation experiments using either an analytical gas chromatography with the FID or the MS. To obtain the concentrated samples, we connected an accessory to the preparative column which consisted of a small volume heated flow diverter and a 1/4-in. outside diameter (OD) stainless steel (SS) trap, together with a heated collector outlet.

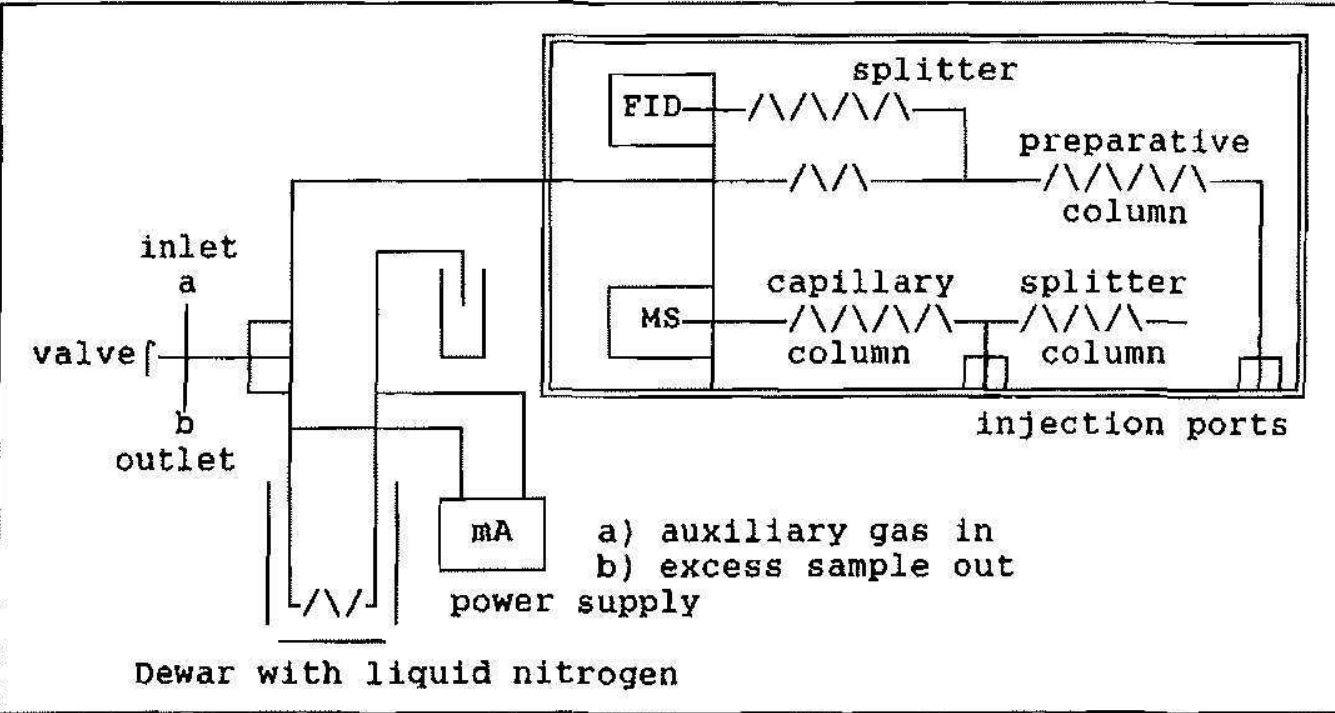

Fig. 1.-GC-MS trap-splitter system with heated collector. 
The following columns were used in the $5750 \mathrm{~A}$ GC:

1) Analytical packed column: PPR-189, $18 \mathrm{ft} \times 1 / 8$ in. OD SS containing 5\% Carbowax 20M coated on 60/80 Chromosorb W. a/w.

2) Preparative column: (a) PPR-191, $10 \mathrm{ft} \times 1 / 4 \mathrm{in}$. OD SS containing $5 \%$ Carbowax 20M coated on 60/80 Chromosorb W. a/w.

A Hewlett Packard (HP-5890A) GC-MS was used to accomplish preparative separation and to evaluate the preparative rum concentrates obtained by the HP-5750GC. It consists of a split/splitless capillary inlet, FID, and HP5970B MSD quadrupole, stand alone GC detector and HP59970C Chemstation with HP5990C computer, hard drive, disk drive and printer. The GC-MS system includes all the necessary software and NBS, NHI, EPA Data Base MS library with mass spectral data for 45,000 compounds. The capillary column used in the $\mathrm{GC} / \mathrm{MS}$ was an SE-30 (methyl silicone) coated on $30 \mathrm{~m} \times 0.25 \mathrm{~mm}$ ID fused silica capillary tubing connected to the MS probe.

To evaluate the proposed setup (fig. 1) employed to separate and identify compounds in rum concentrate obtained with a preparative column, we assembled a trap to allow convenient trapping of samples prior to analysis either with packed analytical or with capillary column. With this system the following tasks were accomplished: samples of rums (1 $\mathrm{ml}$ to $10 \mathrm{ml}$ ) were separated to evaluate the preparative column in terms of the degree of concentration, to evaluate the specific preparativeanalytical configuration, and to perform experiments with the MS-GC system. For these procedures, when the matrix of the sample had eluted from the preparative column the carrier flow was diverted through the small trap kept under liquid nitrogen. The concentrated sample was then passed through the heated collector and-sealed in a small vial kept under liquid nitrogen. The samples were then analyzed with the HP-5750A GC by means of PPR-189 high efficient gas chromatography (HEGC) with the packed column or with the MS-GC by using the PPR-199 capillary column (table 1).

TABLE 1.-Conditions for the chromatographic columns

\begin{tabular}{lccc}
\hline Function & $P P R-189$ & $P P R-191$ & $P P R-199$ \\
\hline Pressure & $60 \mathrm{psi}$ & $60 \mathrm{psi}$ & $12 \mathrm{psi}$ \\
Flow & $50 \mathrm{ml} / \mathrm{min}$ & $50 \mathrm{ml} / \mathrm{min}$ & $1 \mathrm{ml} / \mathrm{min}$ \\
$\mathrm{T}_{\mathrm{i}}$ & $58^{\circ} \mathrm{C}$ & $58^{\circ} \mathrm{C}$ & $50^{\circ} \mathrm{C}$ \\
$\mathrm{T}_{\mathrm{f}}$ & $140^{\circ} \mathrm{C}$ & $150^{\circ} \mathrm{C}$ & $150^{\circ} \mathrm{C}$ \\
Temp. prog. & $20^{\circ} \mathrm{C} / \mathrm{min}$ & $20^{\circ} \mathrm{C} / \mathrm{min}$ & $20^{\circ} \mathrm{C} / \mathrm{min}$ \\
Post inj. time & $2 \mathrm{~min}$ & $12 \mathrm{~min}$ & $12 \mathrm{~min}$ \\
Trapping after & - & $10 \mathrm{~min}$ & $*$ \\
Trapping time & - & $30 \mathrm{~min}$ & $*$ \\
Splitter ratio & - & - & $1: 50$ \\
Sample size & $3 \mu \mathrm{l}$ & Var. & $3 \mu \mathrm{L}$ \\
\hline
\end{tabular}




\section{RESULTS AND DISCUSSION}

On the basis of our experience in the use of preparative columns to concentrate rum from previous investigations $(1,5)$ we used the Carbowax 20M-Chromosorb $\mathrm{W}, \mathrm{a} / \mathrm{w}$ packing. This material allows the separation of fully developed signals with no noticeable contamination from the packing. The HEGC procedure was also derived from previous analytical procedures based on an efficient column to resolve as many signals as possible (4).

The results of the work with the proposed preparative system were excellent after problems connected with sample fractionation were solved by controlling outlet temperature of the effluent. Figure 2 shows a typical preparative chromatogram of $1 \mathrm{ml}$ of R-819 rum taken with the PPR-191 column in the HP-5750A chromatograph. Figure 3 shows analytical separations taken with the PPR-189 column for the same sample in the HP-5750A chromatograph. One of the signals corresponds to the concentrate from $10 \mathrm{ml}$ of rum R-819, and the other belongs to the neat sample. The lower part of figure 3 is the chromatogram of the neat sample, whereas the upper portion represents the chromatogram of the concentrated sample.

The concentrated samples prepared from $1 \mathrm{ml}$ and $0 \mathrm{ml}$ of rum $\mathrm{R}-818$ were also analyzed. Figure 4 shows results of this part of the investigation: for the 1-ml sample, lower portion; and for the 10-ml sample, upper portion. The gas chromatograph-mass spectrometry (GC-MS) of the rum concentrate from $1 \mathrm{ml}$ and from $10 \mathrm{ml}$ of rum $\mathrm{R}-819$ is reproduced in figures 5 and 6 , respectively.

It is evident that the preparative system works properly even when the amount of sample is small (figs. 4, 5, 6), but in order to detect a maximum number of compounds in the concentrated matrix the volume

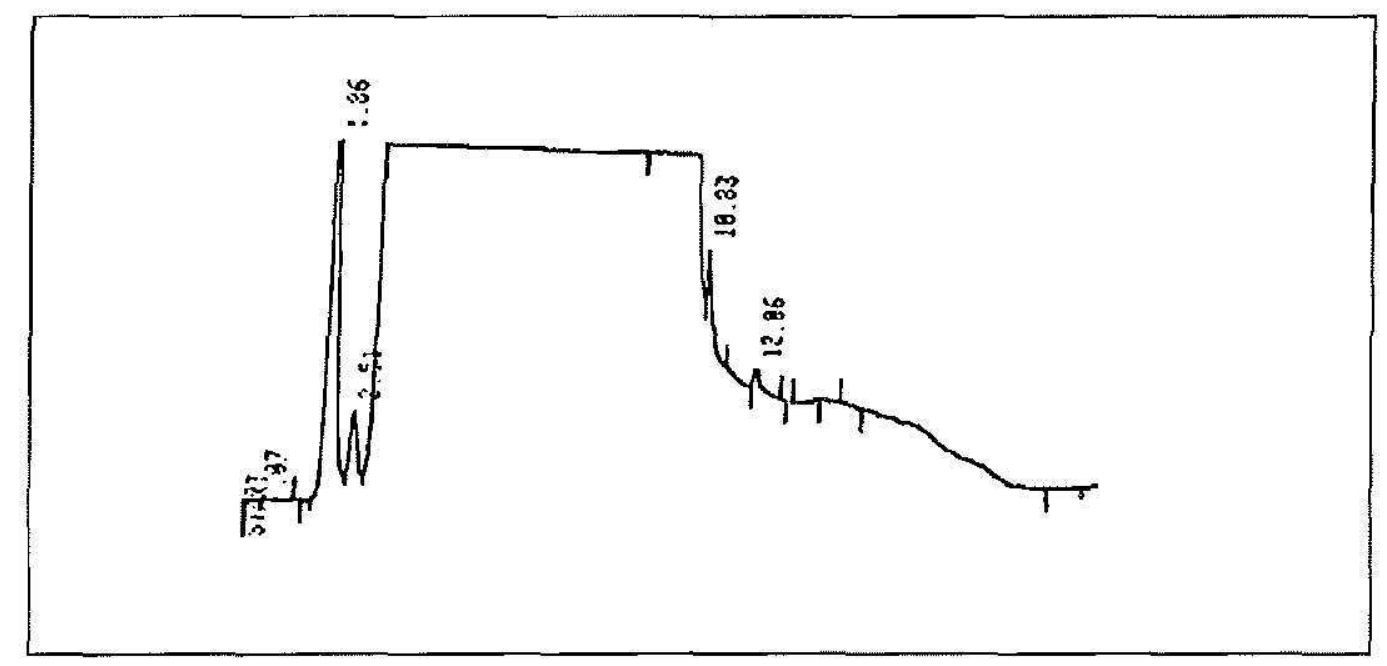

Fig. 2.-Typical preparative chromatogram of $1 \mathrm{ml}$ of R-819 rum taken with PPR-191 column in the HP-5750A chromatograph. 


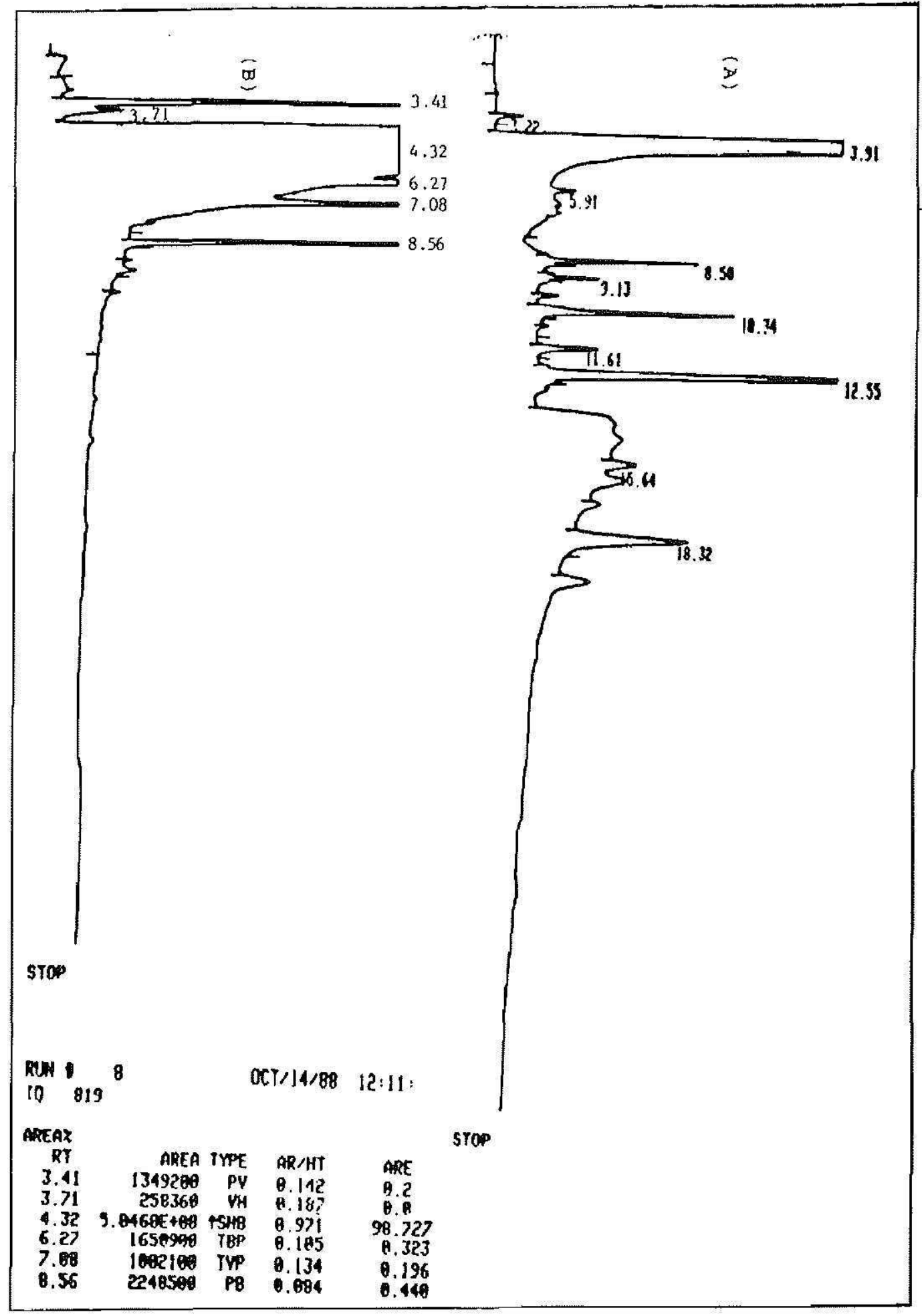

Fig. 3.-Analytical separations taken with PPR-189 column for the same rum sample with the HP-5750A chromatograph; (A) $3 \mu \mathrm{l}$ rum concentrate from $10 \mathrm{ml}$ of rum R-819; and (B) $3 \mu$ l sample of neat R-819 rum. 


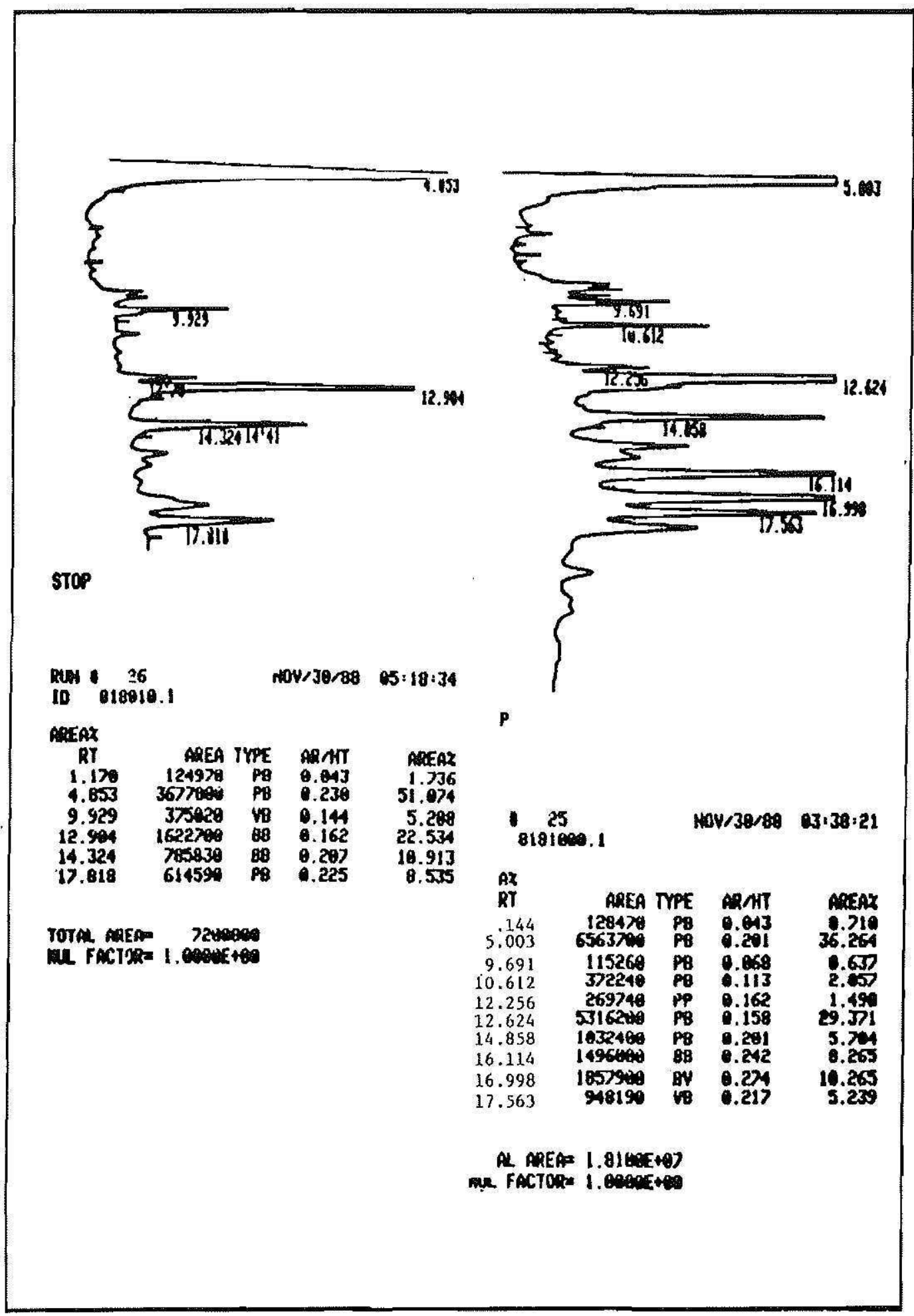

Fig. 4.-Analytical separations of $3 \mu$ l concentrated samples prepared from $1 \mathrm{ml}$ and $10 \mathrm{ml}$ of rum R-818 taken with PPR-189 and HP-5750A. 


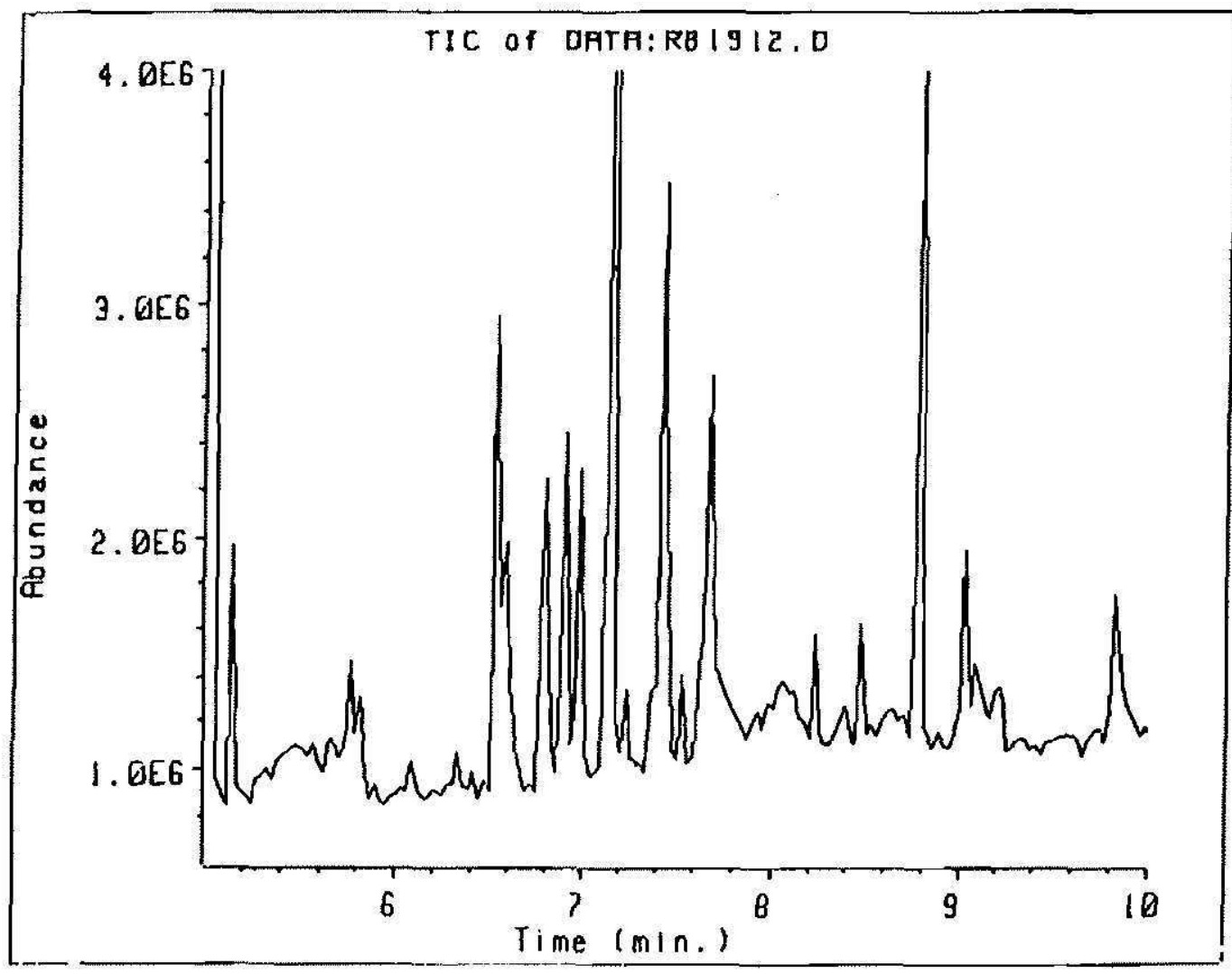
199.

Fig. 5. - The GC-MS of the rum concentrate from $1 \mathrm{ml}$ of rum R-819 taken with PPR-

injected must be as high as $10 \mathrm{ml}$. The present set of preparative chromatographic techniques resulted in about 1000-fold improvement in the concentration of components in their own matrix as shown in fig. 3. Therefore, the vast majority of components resolved with the new technique are at concentrations below $0.01 \mathrm{mg} / 100 \mathrm{ml}$. However, no attempt was made to quantify these components in the present stage of the investigation. This technique was evaluated successfully and numerous components were separated in the different chromatograms which were not observed in previous works.

\section{LITERATURE CITED}

1. Batiz, H., 1979. Analysis of rums with a preparative-capillary system employing a newly developed trap-splitter, J. Agric. Univ. P. R. 63 (4): 294-308.

2. - 1988. Preparative-analytical gas chromatographic techniques for mass spectrometric identification of rum composition. Proc. Sociedad Puertorriqueña de Ciencias Agricolas, Ponce, P.R.

3. - 1989. Preparative-analytical gas chromatography, Rum Pilot Plant, AEE-UPR, Río Piedras, P.R.

4. - and E. Rosado, 1979. A single column gas chromatographic method for the direct trace analysis of high boiling components in rums., J. Agric. Univ. P.R. 63 (2): $330-42$. 


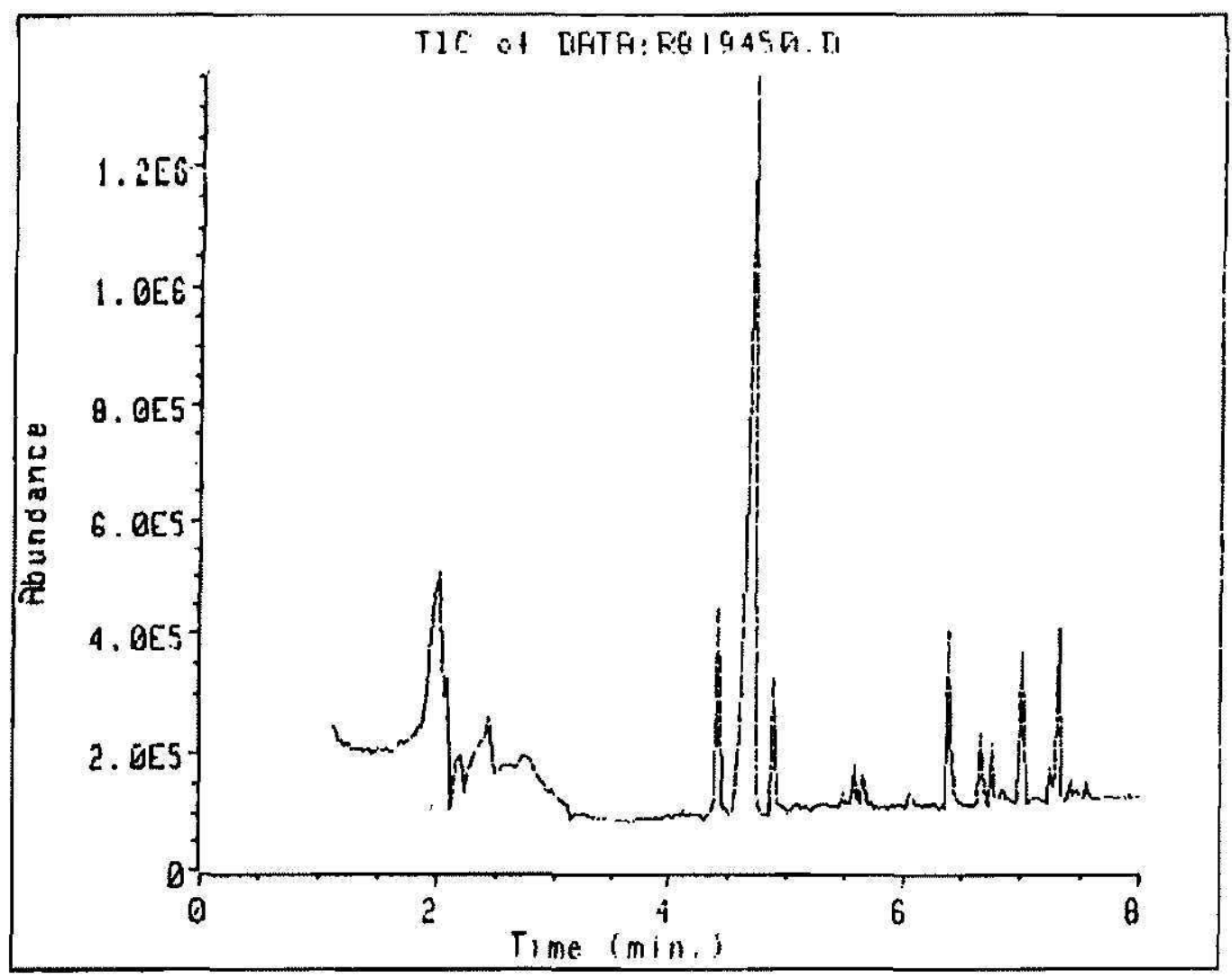

Fig. 6.-The GC-MS of the rum concentrate from $10 \mathrm{ml}$ of rum R-819 taken with PPR-199.

5. — and —, 1977. A trap-splitter unit for coupling preparative gas chromatography columns to analytical columns., J. Agric. Univ. P.R. 61 (1): 108-12.

6. - and E. Soltero, 1976. Preparative-capillary gas chromatographic system for trace analysis of rum, J. Agric. Univ. P.R. 60 (4): 559-84.

7. Brumley, W. C., B. J. Canas, B. A. Perfetti, M. M. Nossoba and J. Sphon, 1988. Quantitation of ethyl carbamate in whiskey, sherry, port, and wine by gas chromatography tandem mass spectrometry using a triple quadrupole mass spectrometry. Anal. Chem., 60 (10): 975-78.

8. Canas, B., D. C. Harvey and F. L. Joe, Jx., 1988. Rapid gas chromatographic method for determining ethyl carbamate in alcoholic beverages with thermal energy analyzer detection. J. Assoc. Anal. Chem., 71, (8) 509-11.

9. Lehtonen, M. and P. J. Ericksson, 1983. Volatile and non-volatile compounds in flavour of alcoholic beverages. Flavour of Distilled Beverages, Origin and Development. Ellis Horwood Limited, 64-78.

10. - and $P$. Lehtomen, 1986. The determination of volatile phenol in rum and brandy by GC y LC. Instrumen. Anal. Foods. 2, 397-407.

11. Nykänen L. and I. Nykänen, 1983. Rum flavour. Flavour of Distilled Beverages, Origin and Development. Ellis Horwood Limited, 49-63.

12. - and H. Suomalainen, 1983. Aroma of beer, wines, and distilled beverages, Akademic-Verlag, Berlin.

13. Piggott, J. R., 1983. Flavour of Distilled Beverages, Origin and Development. Ellis Horwood Limited. 64-78. 